\title{
29
}

\section{The dry and the wet: The variable effect of taphonomy on the dog remains from the Kohika Lake Village, Bay of Plenty, New Zealand}

\author{
Graeme Taylor \\ c/o Anthropology Department, University of Auckland, New Zealand \\ GTaylor@adhb.govt.nz

\section{Geoffrey Irwin} \\ Anthropology Department, University of Auckland, New Zealand
}

\section{Introduction}

Since the mid 1980s, there have been several detailed taphonomic studies on New Zealand faunal assemblages, summarised by Allen and Nagaoka (2004:207-209), and these, not surprisingly given the breadth of his zooarchaeological publications, have included a contribution by Atholl Anderson (Anderson et al. 1996). However, most of these studies have been concerned with bones recovered from dry-land sites, whereas bone preserved under very different conditions in wetland archaeological sites has received little consideration.

This paper examines the dog-bone assemblages recovered from the site of Kohika V15/80 during three Auckland University excavations between 2005 and 2007. Kohika was a 17th century Maori lake village on a low island near the southern shore of Lake Kohika in the Bay of Plenty, New Zealand. It was abandoned after a flood and fortuitously preserved in peat, and then remained undisturbed until agricultural drainage in 1974. Excavations were carried out at the site between 1974 and 1981, and the diversity of the evidence uncovered and the specialist analysis done on the material revealed extensive information about the economic, domestic and social activities of a community that existed well before the advent of the pakeha (Irwin 2004a). Although the site is best known for its well-preserved wooden and fibre artefacts, these first excavations also recovered almost 200 dog bones, which Clark (1995:272) described as the most complete and best-preserved collection of dog remains from any site in the country.

The more recent excavations have doubled the size of this assemblage and the collection now 
includes a significant number of bones from both the wetland and dry-land parts of the site. In this paper, the dog bones from these different parts of Kohika, especially those recovered since 2005, are compared. This intra-site comparison not only provides an insight into the variable taphonomic processes operating at Kohika, but also provides a window into the taphonomic effects which may have been operating at many other New Zealand sites with less optimal bonepreservation conditions.

The island of Kohika is shown in Figure 1, and its core is a remnant of the 2000 BP shoreline left stranded by a prograding coast. At the time of occupation, the site was surrounded by swamp and a shallow fresh-water lake, and lightly defended with a palisade. There were households located around the shore, typically with houses, raised pataka storehouses and miscellaneous shelters. Canoes were drawn up at the shore and excavations have revealed formed landing places beside entrances through the palisade. Figure 2 shows the bay on the northern side of the site, which was an area of concentrated activity in prehistory. Since 2005, the excavations at Kohika have been mainly in two areas, known as Area D and Area E. Area D was located in the former lake, as it was during the occupation of the village, and many wooden and fibre artefacts, and other ecofacts were recovered from an anaerobic environment of peat and lacustrine silt. In contrast, Area E was located on dry land on the adjacent shore and generally inside the palisade. Figure 2 shows one house, a carefully constructed marae structure and other buildings. The deposit of Area $\mathrm{E}$ was aerobic and composed largely of marine dune sand and reworked tephra, and it yielded large numbers of artefacts of obsidian, pounamu greenstone and bone. Figure 2 also shows the location of the Area D excavations of the 1970s, where much of the deposit also consisted of peat of the former lake, but there were artificially laid sand platforms of a former household as well (Irwin 2004a).

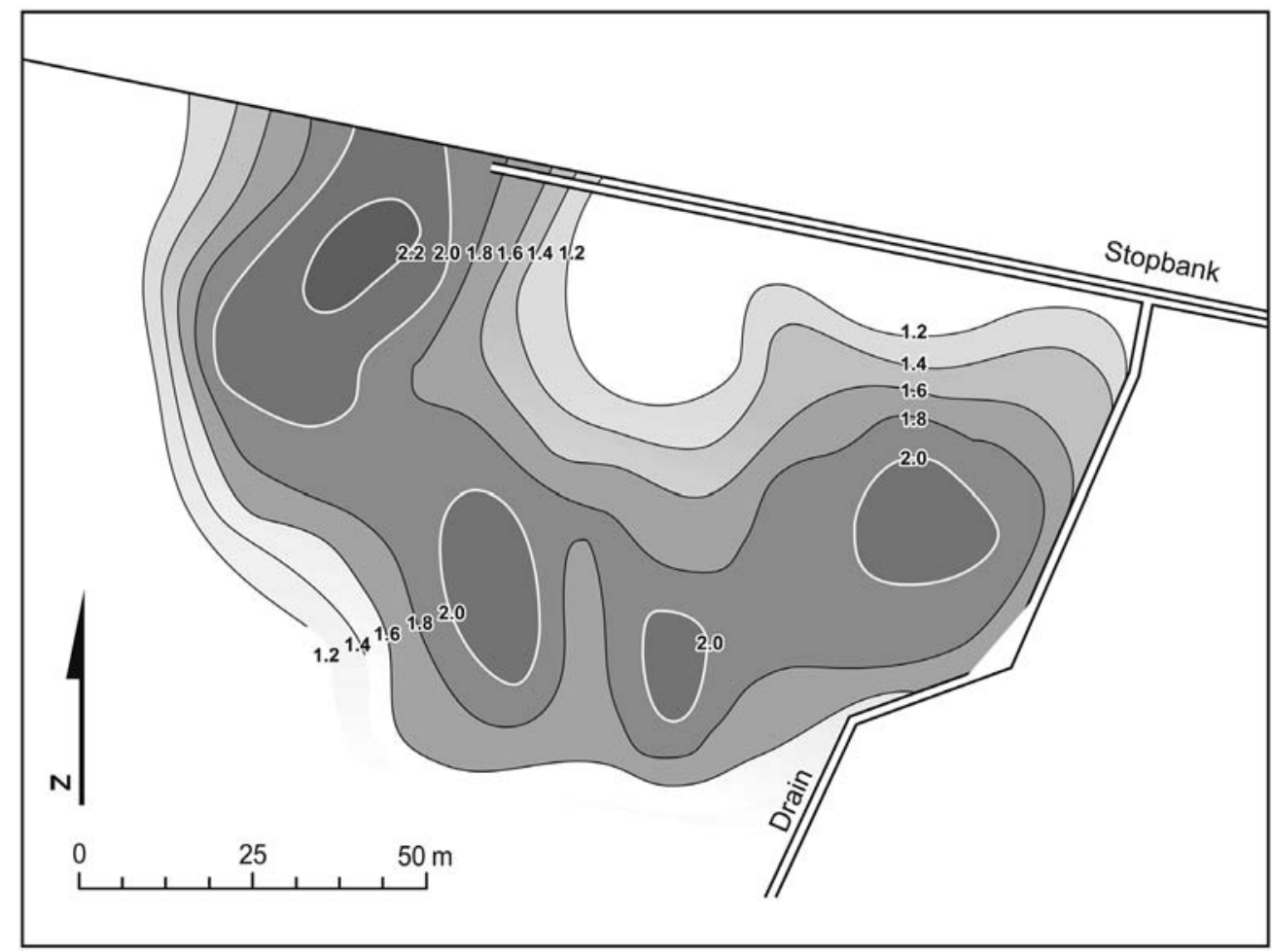

Figure 1. Kohika was a low island surrounded by shallow lake and swamp in the fork of the Rangitaiki and Tarawera rivers, which entered the sea through a common river mouth nearby. Its location gave easy access by canoe to local resources, and good communications into the central North Island of New Zealand and along the Bay of Plenty coast. 


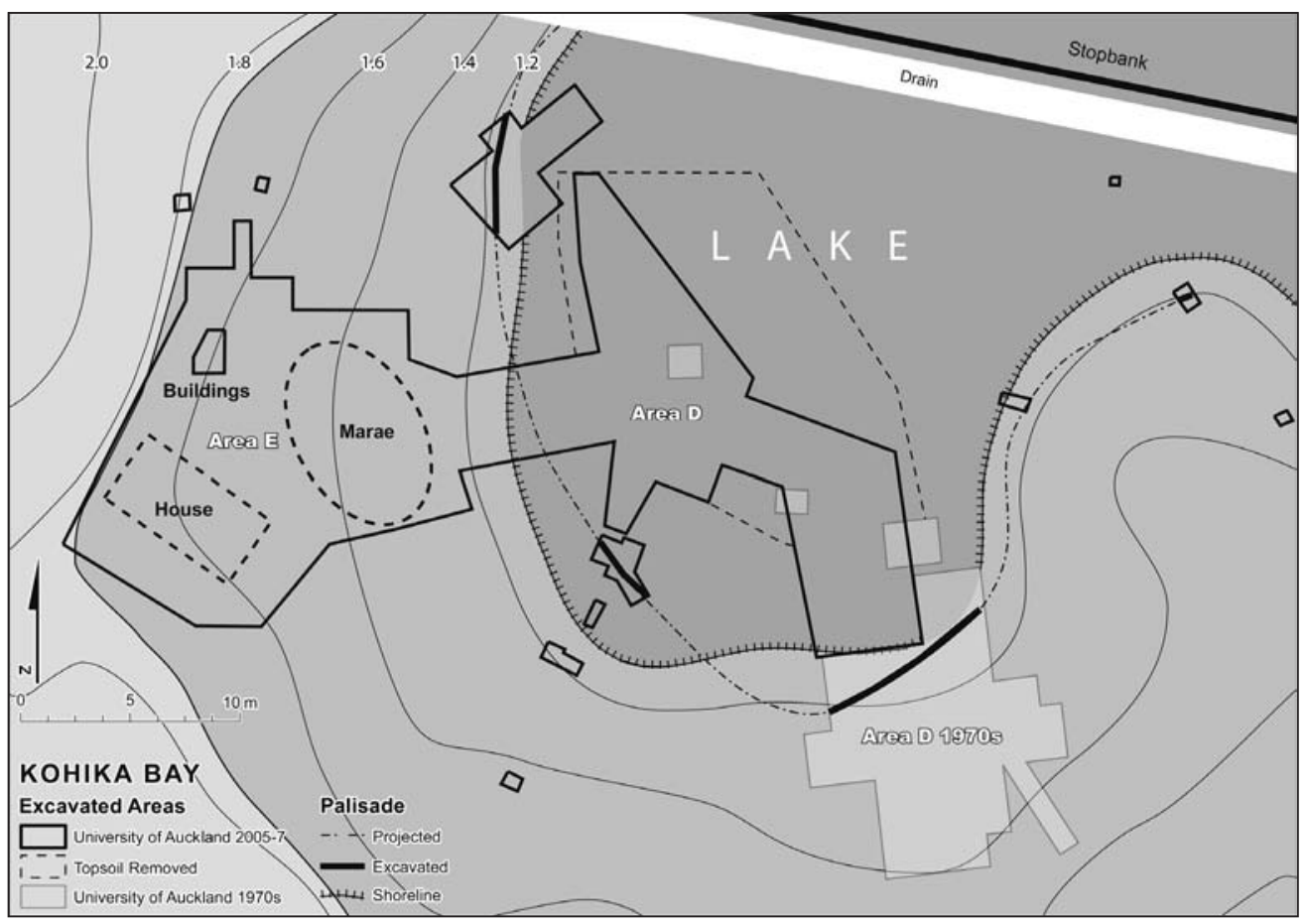

Figure 2. Excavations 2005-2007 were concentrated around a former bay on the north of the island. Area D consisted of waterlogged deposits in the area of the former lake. Area E revealed a household on the adjacent dry shore. There were formed canoe landings at the lake edge and entrances through a light palisade. The locations of the Area D excavations of the 1970 s are also shown.

\section{Methods}

The provenience of each bone or bone artefact recovered during the 2005-2007 excavations was recorded with a total station. After being cleaned and dried, each of these bones and bone artefacts was identified by element (where possible), using the zooarchaeological comparative collection housed in the Auckland University Anthropology Department. In addition, each bone specimen was examined for evidence of $\operatorname{dog}$ or rat gnawing, weathering and cultural modifications, including cut, saw or chop marks, drill holes, filing and burning. For the dog remains, skeletal maturity was assessed using the criteria established by Clark (1995:62-64) for mandibles and crania, by Clark (1997:205) for long bones, and by Allo (1970:34) for tooth eruption.

The number of identified specimens (NISP) was defined as any element or any parts of a single element which could be refitted, with a single shot number (as recorded by the total station). This definition allowed for any bone breakage during and subsequent to excavation. The minimum number of elements (MNE) was determined by calculating the most frequently occurring part of an element. For example, dog tibiae were divided into proximal and distal ends and shafts for both the right and left sides. If the collection of right dog tibiae consisted of seven proximal ends, six shafts and five distal ends, then the MNE for right dog tibiae was seven. If a similar calculation for left tibiae gave an MNE of five, the total MNE for dog tibiae was 12. The minimum number of individuals (MNI) was represented by either the MNE for unpaired elements or the largest MNE for paired elements. Using the dog-tibiae example, the MNI for dogs would be seven based on the presence of seven right tibiae. However, it was sometimes possible to increase the MNI by considering mature and immature specimens. For example, if 
all seven right proximal tibiae came from mature dogs but two of the five left proximal tibiae came from immature dogs, then the MNI would be nine (seven right proximal tibiae, plus two unmatched immature left proximal tibiae).

\section{Results}

Dog remains recovered from Areas D and E from 2005-2007

Table 1 shows that the minimum number of dogs identified in the Kohika excavations from 2005 to 2007 is 20 , based on left mandibles. To get an idea of the relative frequency with which some dog-bone elements have been recovered compared with others it is useful to graph the MNIs derived from each element, as shown in Figure 3.

Both Table 1 and Figure 3 show there is significant variation in the frequency with which particular dog bones have been recovered. Mandibles were at least two to three times more likely to have been recovered than crania, any of the long bones, the pelves, or the first and second cervical vertebrae. A third group of bones, including scapulae, ribs, vertebrae other than $\mathrm{C} 1$ or $\mathrm{C} 2$, and the small bones of the feet, were under-represented to an even greater extent.

\section{Comparison of dog bones from Areas D and $\mathrm{E}$}

In addition to comparing the relative frequencies of various elements across the whole site, it is useful to compare the MNE for each element in Area D and Area E, given that Area D was in the lake and the bones from this part of the site were recovered from anaerobic peat, while the bones from Area $\mathrm{E}$ were located inside the village palisade in an aerobic and often sandy environment. The MNE for the various dog elements in Areas D and E are presented in Table 2 and Figure 4.

As shown, there is a pronounced difference in the proportions of the various dog bones found in Areas D and E, even though these two areas were of approximately equal size (Table 2 and Figure 4). Only mandibles, radii and the $\mathrm{C} 1$ and $\mathrm{C} 2$ cervical vertebrae were found in greater numbers in Area E, and of these, mandibles were three times as frequent as any other single element. In contrast, all the scapulae and ribs and virtually all the crania, pelves and vertebrae, other than $\mathrm{C} 1$ and C2 vertebrae, were found in Area D. Moreover, with the exception of radii, long bones were at least twice as likely to be recovered from Area D as Area E. Although mandibles were relatively frequent in Area D, they were not as dominant as in Area E, and the MNIs derived from mandibles, pelves and crania in Area D were roughly equivalent (MNI respectively 10,9 and 8 ).

The differences in bone-recovery patterns between Areas D and $\mathrm{E}$ are also highlighted by the proportion of whole or near-whole bones (greater than 90 percent of the element intact) identified within the two areas, as outlined in Table 3.

As illustrated by Table 3, the great majority of whole or near-whole bones was found in Area $\mathrm{D}$ and whole bones were almost six times more likely to have come from this part of the site than from Area E. Furthermore, of the whole or near-whole bones identified in Area E, just over half were mandibles.

The proportions of mature and immature dog bones identified in Areas D and E can also be compared. Twenty osteologically immature dog bones were recovered, and all 20 came from Area $\mathrm{D}$, including eight bones found together from a single individual of about six months of age. No immature dog bones were found in Area E.

Aside from contrasting the frequencies of different elements and the proportions of whole bones and immature bones within the two areas, the extent to which the bones from Areas D and $\mathrm{E}$ were weathered and gnawed by animals can be evaluated. 
Bone-weathering patterns have been described by Behrensmeyer (1978), who proposed six weathering stages. The main changes, in the approximate order they occur, include: hair-line cracks on the bone surface perpendicular to the long axis of the bone, flaking of the cortical surface, and cracks through the full thickness of the cortex, after which the bones fall apart. The proportion of weathered bones in Areas $\mathrm{D}$ and $\mathrm{E}$ is shown in Table 4.

Table 4 shows a significant proportion of the bones from Area $\mathrm{E}$ was weathered, whereas virtually none of the bones from Area $\mathrm{D}$ was affected. Moreover, the single weathered bone from Area $\mathrm{D}$ was only lightly weathered, whereas a small proportion of the Area $\mathrm{E}$ bones were so weathered they were falling apart (Figure 5). Across the whole site, 15 percent of bones were weathered.

In addition to weathering, bone attrition as a consequence of animal gnawing is an important taphonomic variable. In the setting of New Zealand prehistory, the gnawing of bones by dogs and Polynesian rats has been most thoroughly examined by M. Taylor (1984) in reference to the bone assemblage from Twilight Beach in Northland. Dogs prefer to chew the epiphyseal ends of long bones and gnawed bones characteristically demonstrate crenulated edges, tooth puncture marks and irregular scratches and pits where the teeth have been dragged across the bone surface. In contrast to dogs, rats prefer to gnaw bone diaphyses (shafts) and leave a series of parallel, closely spaced, flat-bottomed grooves. The proportions of dog and rat-gnawed bones from Areas D and $\mathrm{E}$ are outlined in Table 5.

Although Table 5 shows there was little difference in the proportions of dog-gnawed bones in Area D and Area E, the extent to which bones had been reduced as a result of dog gnawing did differ. Most dog-gnawed bones in Area D were relatively intact (see Figure 6 and Figure 7), however, with the exception of mandibles, many dog-gnawed bones in Area E had been quite markedly reduced (see Figures 8-12). Rat gnawing was also exclusively found on bones from Area E. Across the whole site, 24 percent of bones showed evidence of dog gnawing and 7 percent demonstrated rat gnawing.

In addition to the proportion of dog-gnawed bones, another notable feature of the assemblage was the consistent pattern of dog gnawing found on particular elements. As noted by Taylor (1984:92), the epiphyseal ends of long bones were certainly favoured (Figure 8), but specific gnawing patterns were also identified on mandibles, crania and pelves. For example, dog-gnawed mandibles were frequently broken through the canine cavity. These irregular breaks contrasted sharply with the pattern of sawing and breakage associated with purposeful removal of the canines by humans (Figure 12). A number of dog-gnawed, but relatively preserved, pelves and crania found in Area D also showed consistent patterns of damage. The gnawed pelves were invariably missing the medial end of the pubis and the cranial end of the ilium (Figure 6), while the gnawed crania were often missing the rostral end of the snout and the zygomatic arches (Figure 7).

A further taphonomic variable which can be compared between Areas D and E is the modification of dog bones by human sawing. Although evidence of burning, chopping and drilling were also sought, there was only a single burnt dog bone, one drilled canine and a single femur with a chop mark, so these factors are not further considered. Moreover, cut marks, which were present on 20 percent of dog bones across both areas, are not considered further either, as they have little influence on the rates of bone survival. Saw marks are defined as deep grooves made by repeatedly moving a blade back and forth in the same cut (Taylor 1984:100). There is usually a set of shallower, parallel striations adjacent to the main saw mark where the blade has jumped out of its intended track when the sawing process began. 
Table 1. Dog bones recovered from Kohika 2005-2007.

\begin{tabular}{|c|c|c|c|c|}
\hline Element & NISP & MNE & MNI & Side used for MNI \\
\hline Crania & 15 & 9 & 9 & \\
\hline Mandibles & 49 & 35 & 20 & left \\
\hline Humeri & 13 & 12 & 7 & right \\
\hline Radii & 10 & 9 & 6 & right \\
\hline Ulnae & 15 & 14 & 9 & left \\
\hline Femora & 14 & 12 & 7 & right \\
\hline Tibiae & 14 & 10 & 8 & left ${ }^{*}$ \\
\hline Pelves & 17 & 17 & 9 & right \\
\hline Scapulae & 6 & 6 & 4 & left \\
\hline Ribs & 7 & 7 & 1 & \\
\hline C1 (atlas) & 7 & 7 & 7 & \\
\hline C2 (axis) & 6 & 6 & 6 & \\
\hline Other cervical vertebrae & 6 & 6 & 2 & \\
\hline Thoracic vertebrae & 3 & 3 & 1 & \\
\hline Lumbar vertebrae & 6 & 6 & 1 & \\
\hline Caudal vertebrae & 1 & 1 & 1 & \\
\hline Metapodials & 6 & 6 & 1 & \\
\hline Calcaniae & 1 & 1 & 1 & \\
\hline Canines & 11 & 11 & 3 & \\
\hline
\end{tabular}

${ }^{*}$ MNI for tibiae consisted of six left tibiae plus two unmatched immature right tibiae

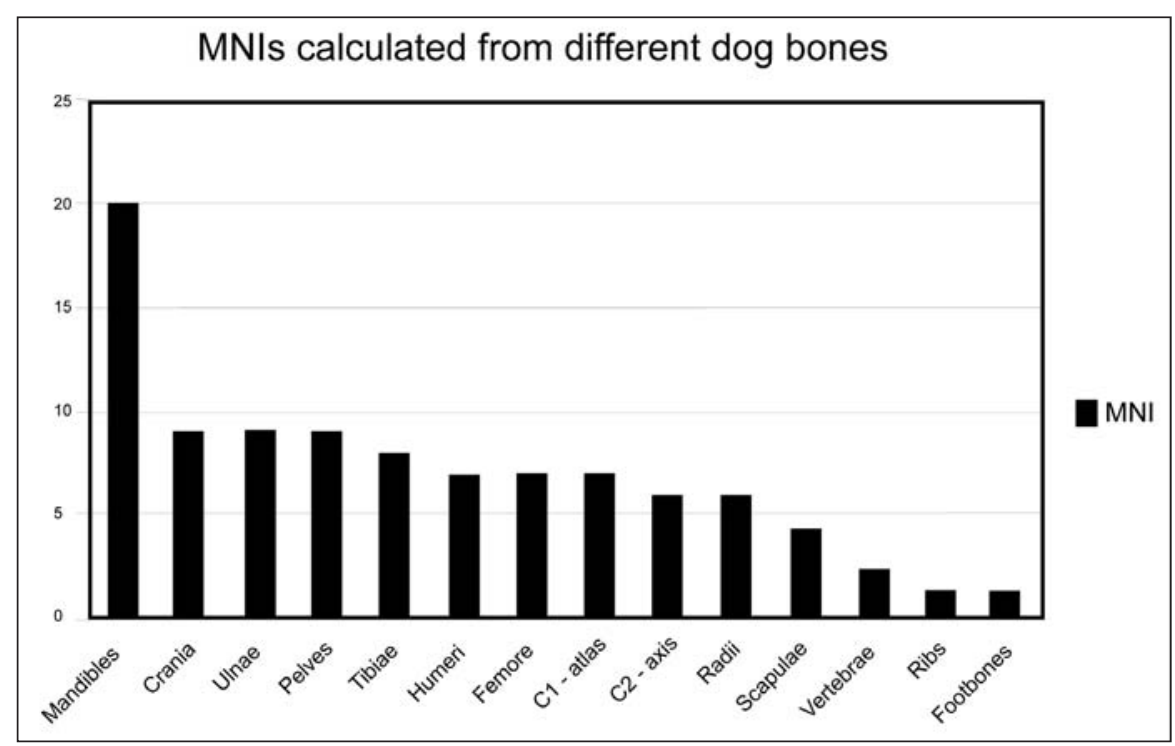

Figure 3. Comparison of MNIs derived from different dog bones, Kohika 2005-2007. 
Table 2. MNE for different dog bones in Area D versus Area $\mathrm{E}$.

\begin{tabular}{lll}
\hline Element & MNE Area D & MNE Area E \\
\hline Crania & 8 & 1 \\
Mandibles & 17 & 18 \\
Humeri & 10 & 2 \\
Radii & 3 & 6 \\
Ulnae & 10 & 4 \\
Femora & 8 & 4 \\
Tibiae & 8 & 4 \\
Pelves & 16 & 1 \\
C1 and C2 vertebrae & 6 & 7 \\
Other vertebrae & 15 & 1 \\
Scapulae & 6 & 0 \\
Ribs & 7 & 0 \\
Distal limb bones & 5 & 2 \\
\hline
\end{tabular}

Table 3. Number of whole or near-whole bones from Area D versus Area E.

\begin{tabular}{lll}
\hline Element & Area D & Area E \\
\hline Crania & 5 & 0 \\
Mandibles & 15 & 8 \\
Humeri & 10 & 0 \\
Radii & 3 & 0 \\
Ulnae & 8 & 0 \\
Femora & 7 & 1 \\
Tibiae & 5 & 0 \\
Pelves & 6 & 0 \\
C1and C2 vertebrae & 6 & 4 \\
Other vertebrae & 11 & 0 \\
Scapulae & 5 & 0 \\
Ribs & 2 & 0 \\
Distal limb bones & 5 & 2 \\
\hline Total & $\mathbf{8 8}$ & $\mathbf{1 5}$ \\
\hline
\end{tabular}

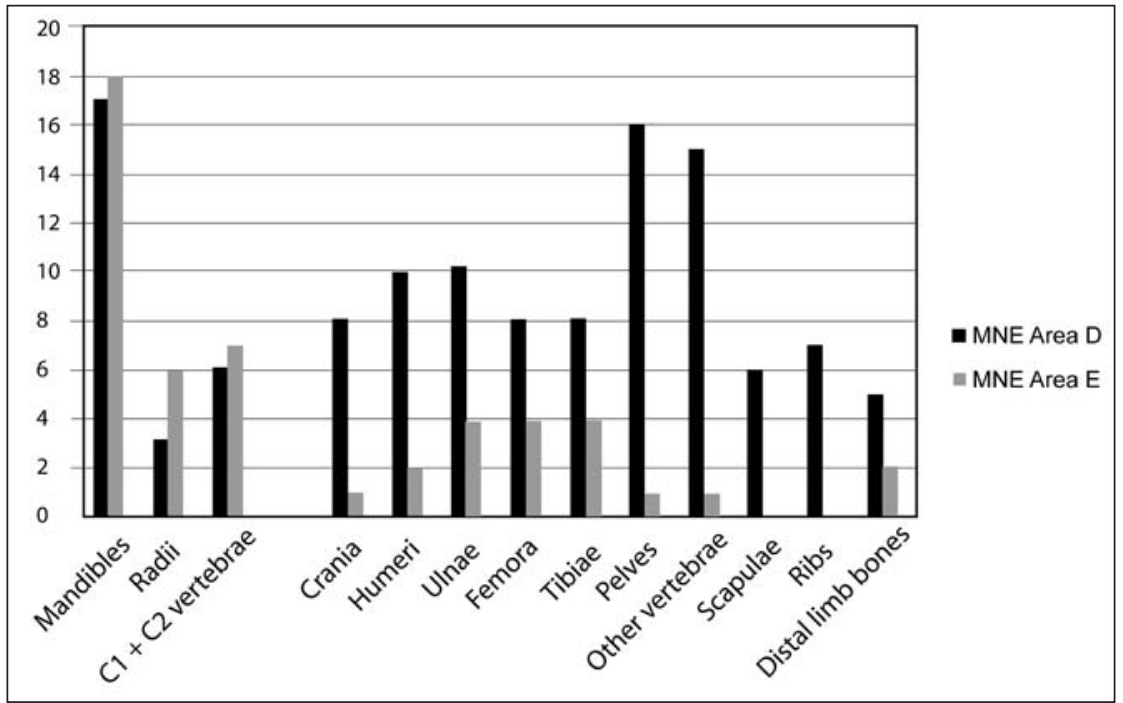

Figure 4. MNE for different dog bones in Area D versus Area E. 
Table 4. Number of weathered bones Area D versus Area E.

\begin{tabular}{|c|c|c|c|c|}
\hline Element & NISP Area D & No. weathered & NISP Area E & No. weathered \\
\hline Crania & 11 & 0 & 4 & 0 \\
\hline Mandibles & 17 & 0 & 32 & 8 \\
\hline Humeri & 10 & 0 & 3 & 2 \\
\hline Radii & 3 & 0 & 7 & 1 \\
\hline Ulnae & 10 & 1 & 5 & 3 \\
\hline Femora & 9 & 0 & 5 & 3 \\
\hline Tibiae & 8 & 0 & 6 & 2 \\
\hline Pelves & 16 & 0 & 1 & 1 \\
\hline $\mathrm{C} 1 / \mathrm{C} 2$ vertebrae & 6 & 0 & 7 & 4 \\
\hline Other vertebrae & 15 & 0 & 1 & 0 \\
\hline Scapulae & 6 & 0 & 0 & 0 \\
\hline Ribs & 7 & 0 & 0 & 0 \\
\hline Distal limb bones & 5 & 0 & 2 & 0 \\
\hline Canines & 2 & 0 & 9 & 7 \\
\hline Total & 125 & $1(0.8 \%)$ & 82 & $31(38 \%)$ \\
\hline
\end{tabular}

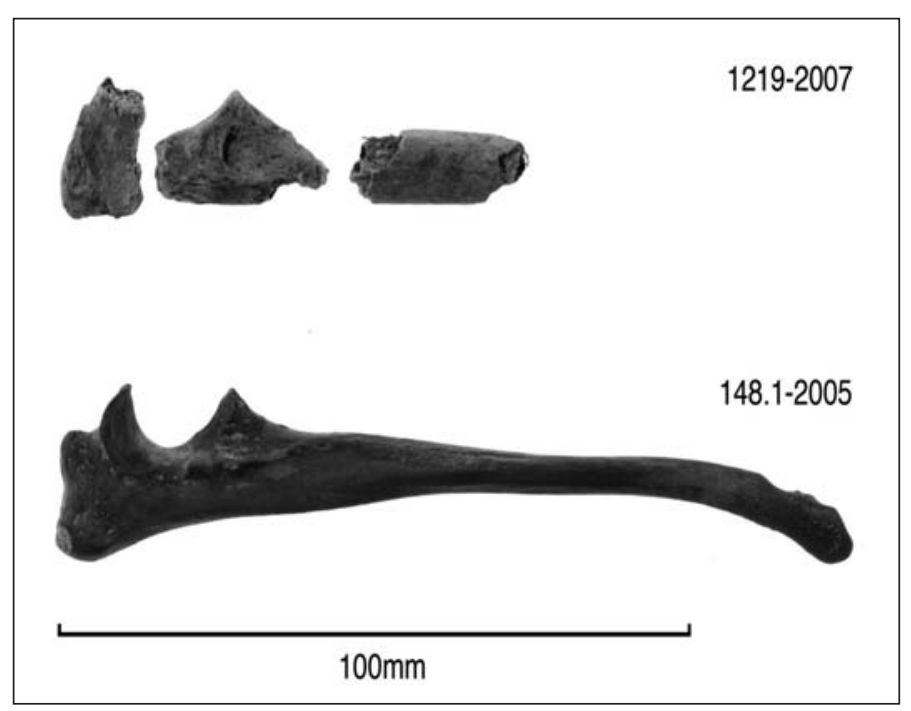

Figure 5. Two dog ulnae showing the effect of weathering on bones in Area $E$ compared with Area D. The lower ulna comes from Area D and is typical of the non-weathered bones from this part of the site. The upper ulna, from Area $E$, is markedly weathered and is falling apart. 
Table 5. Number of dog and rat-gnawed bones Area D versus Area E.

\begin{tabular}{|c|c|c|c|c|c|c|}
\hline Element & NISP Area D & No. dog gnawed & No. rat gnawed & NISP Area E & No. dog gnawed & No. rat gnawed \\
\hline Crania & 11 & 6 & 0 & 4 & 2 & 0 \\
\hline Mandibles & 17 & 2 & 0 & 32 & 9 & 4 \\
\hline Humeri & 10 & 0 & 0 & 3 & 2 & 2 \\
\hline Radii & 3 & 1 & 0 & 7 & 0 & 0 \\
\hline Ulnae & 10 & 1 & 0 & 5 & 0 & 1 \\
\hline Femora & 9 & 0 & 0 & 5 & 3 & 2 \\
\hline Tibiae & 8 & 4 & 0 & 6 & 1 & 1 \\
\hline Pelves & 16 & 11 & 0 & 1 & 1 & 0 \\
\hline C1/C2 vertebrae & 6 & 0 & 0 & 7 & 3 & 2 \\
\hline Other vertebrae & 15 & 0 & 0 & 1 & 0 & 0 \\
\hline Scapulae & 6 & 2 & 0 & 0 & 0 & 0 \\
\hline Ribs & 7 & 1 & 0 & 0 & 0 & 0 \\
\hline Small limb bones & 5 & 0 & 0 & 2 & 0 & 0 \\
\hline Canines & 2 & 0 & 0 & 9 & 0 & 3 \\
\hline Totals & 125 & $28(22 \%)$ & $0(0 \%)$ & 82 & $21(26 \%)$ & $15(18 \%)$ \\
\hline
\end{tabular}

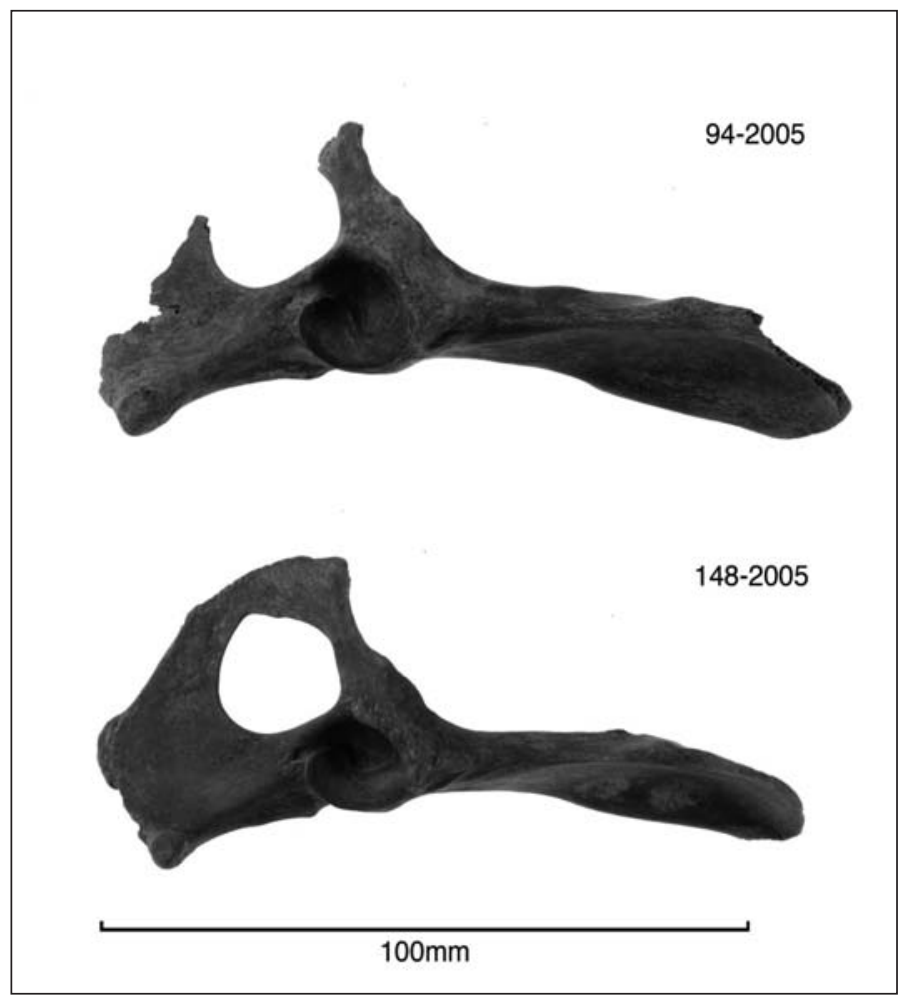

Figure 6. An intact dog hemipelvis from Area $D$ on the bottom and a doggnawed hemipelvis from Area D on the top. Note the typical loss of the medial end of the pubis and the cranial end of the ilium in the latter specimen. 
Table 6. Number of dog bones with saw marks in Area D versus Area $E$.

\begin{tabular}{llllll}
\hline Element & Area D NISP & No. with saw marks & Area E NISP & No. with saw marks & $\begin{array}{l}\text { Percentage worked } \\
\text { (both Areas) }\end{array}$ \\
\hline Crania & 11 & 0 & 4 & 0 & $0 \%(0 / 15)$ \\
Mandibles & 17 & 2 & 32 & 10 & $24 \%(12 / 49)$ \\
Humeri & 10 & 0 & 3 & 1 & $8 \%(1 / 13)$ \\
Radii & 3 & 0 & 7 & 6 & $60 \%(6 / 10)$ \\
Ulnae & 10 & 0 & 5 & 0 & $0 \%(0 / 15)$ \\
Femora & 9 & 0 & 5 & 4 & $14 \%(2 / 14)$ \\
Tibiae & 8 & 0 & 6 & 0 & $29 \%(4 / 14)$ \\
Pelves & 16 & 0 & 1 & 0 & $0 \%(0 / 17)$ \\
Vertebrae & 21 & 0 & 8 & 0 & $0 \%(0 / 29)$ \\
Scapulae & 6 & 0 & 0 & 0 & $0 \%(0 / 6)$ \\
Ribs & 7 & 0 & 0 & 0 & $0 \%(0 / 7)$ \\
Small limb bones & 5 & 0 & 2 & $\mathbf{2 4}$ & $0 \%(0 / 7)$ \\
Canines & 2 & 0 & $929 \%)$ & $18 \%(2 / 11)$ \\
\hline Total & 125 & $2(1.6 \%)$ & $13 \%(26 / 207)$ \\
\hline
\end{tabular}

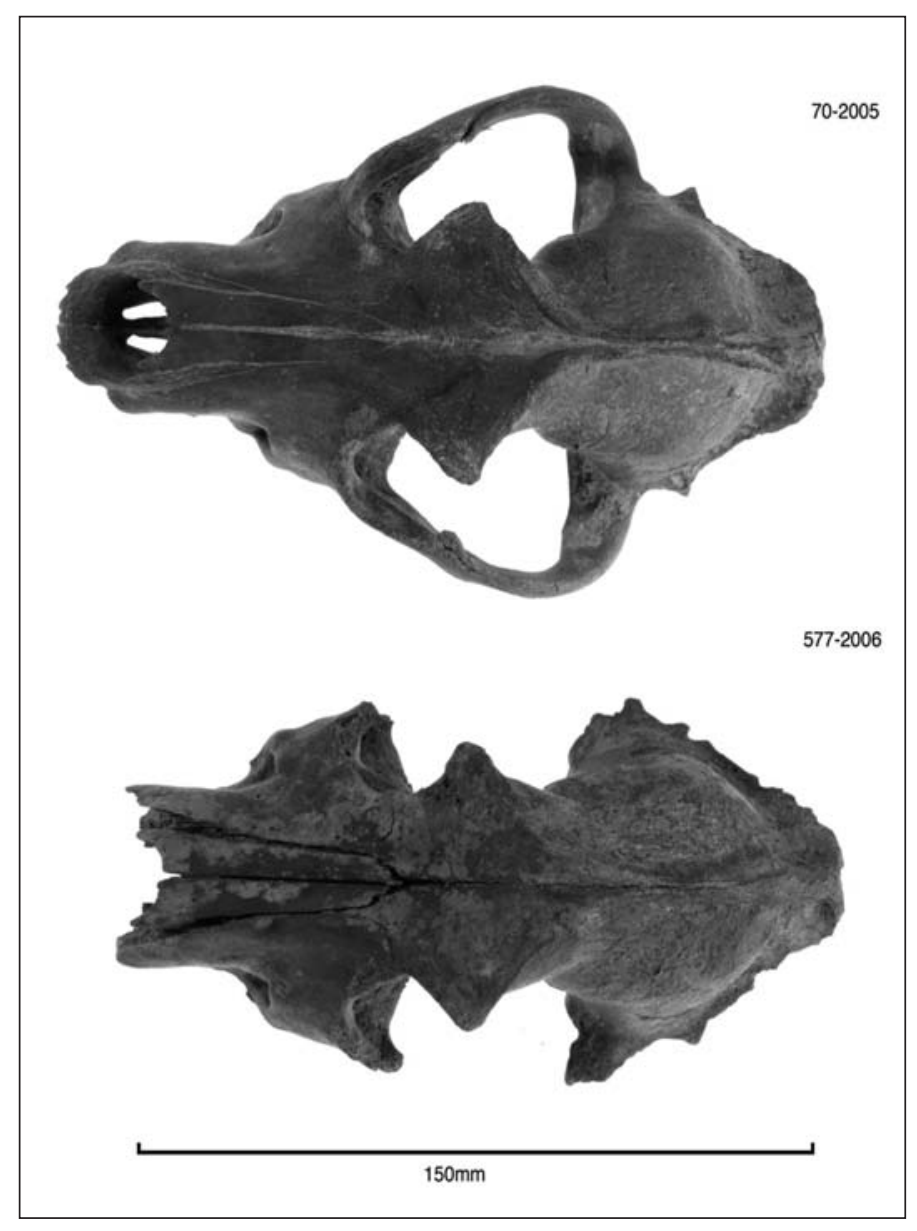

Figure 7. An intact cranium from Area $D$ on the top and a dog-gnawed cranium from Area D on the bottom. The loss of the rostral end of the snout and the zygomatic arches in the latter specimen were often identified in dog-gnawed crania. 

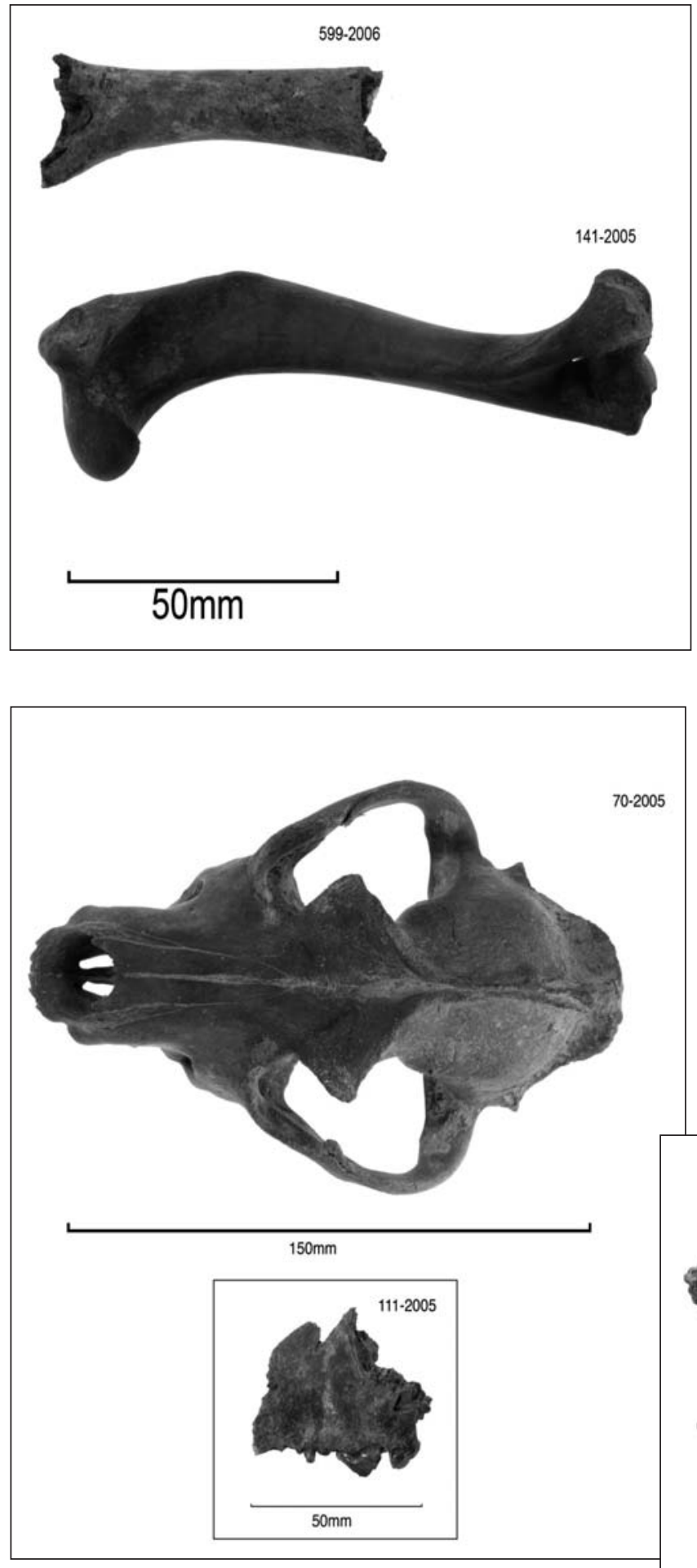

Figure 10 (right). 0 n the bottom is a completely intact hemipelvis from Area D, while the fragment on the top, which includes part of the left acetabulum, is dog gnawed and weathered and represents the only fragment of pelvis found in Area $E$ (compare with the doggnawed pelves in Area D as shown in Figure 6).
Figure 8. A completely intact dog humerus from Area $D$ on the bottom compared with a dog-gnawed humerus from Area $\mathrm{E}$ on the top. The latter shows the characteristic loss of both epiphyseal ends and also represents the largest fragment of humerus found in Area $E$.

Figure 9 (left). The cranium on the top is the best-preserved example of a dog skull from Area $D$, whereas the dog-gnawed fragment of left maxilla on the bottom represents one of the two largest cranial fragments found in Area $E$ (compare with the doggnawed crania in Area D, as shown in Figure 7).
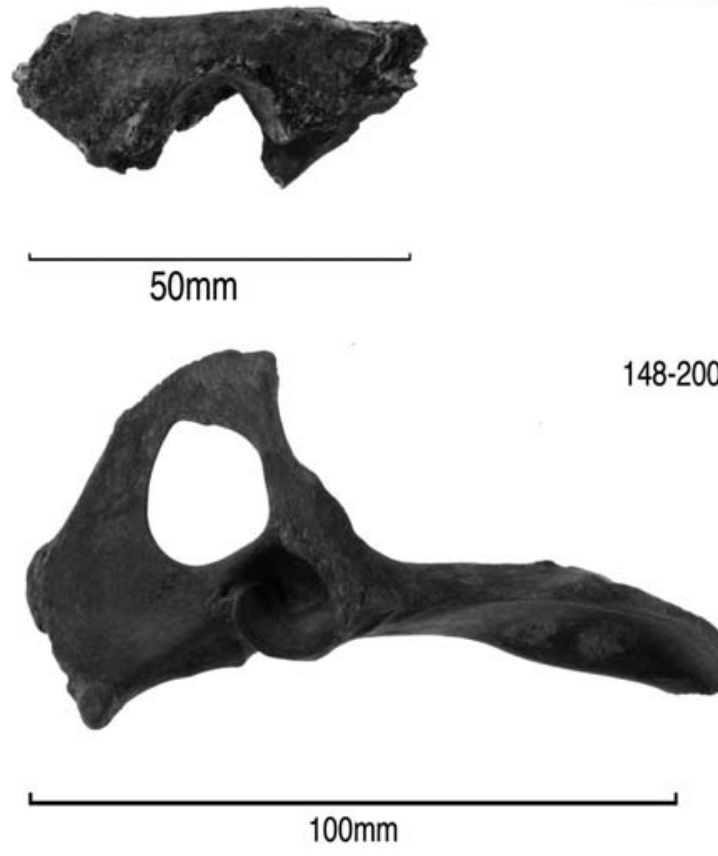


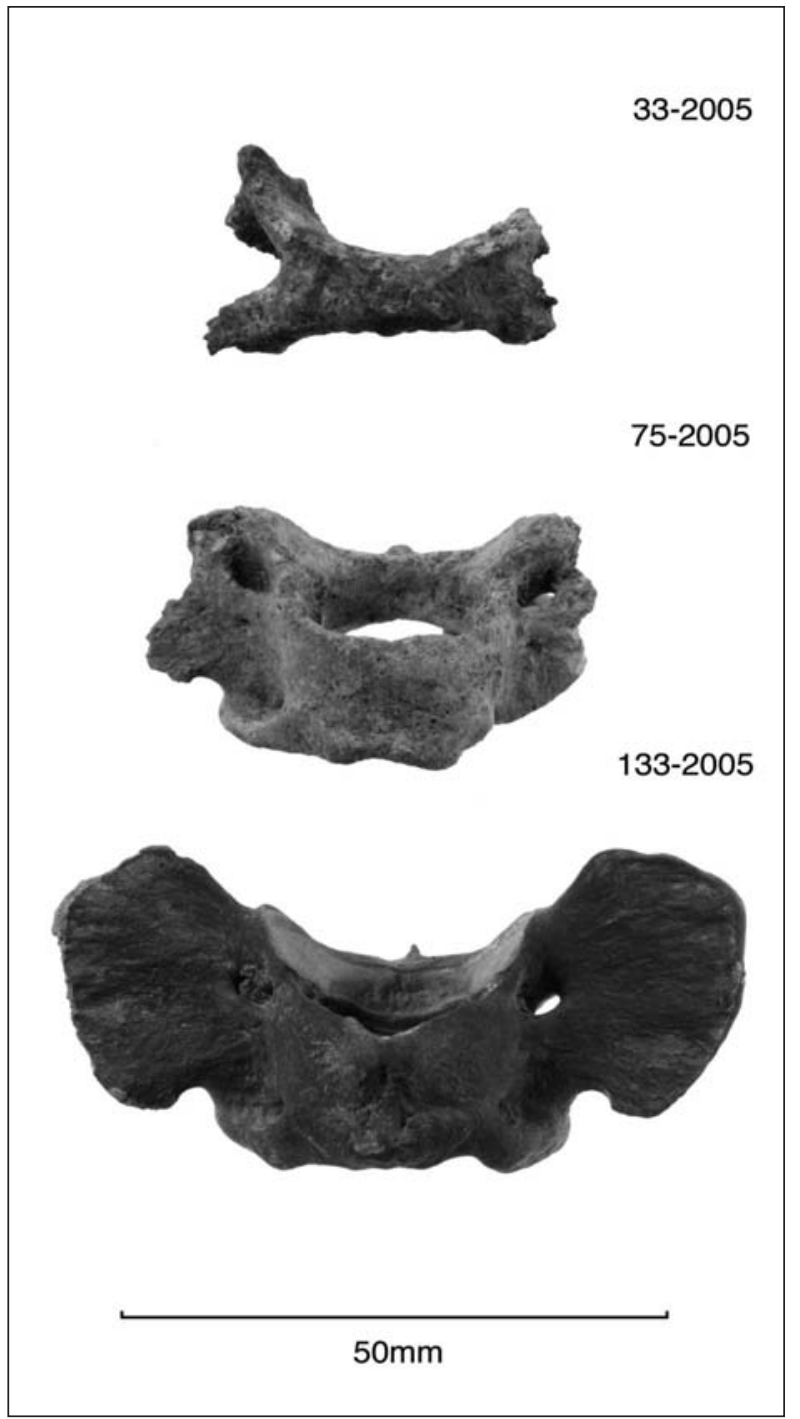

Figure 11. Three $\mathrm{C} 1$ cervical vertebrae (axes). The bottom bone is intact and comes from Area D, whereas the top two are both dog gnawed and weathered and come from Area $\mathrm{E}$.

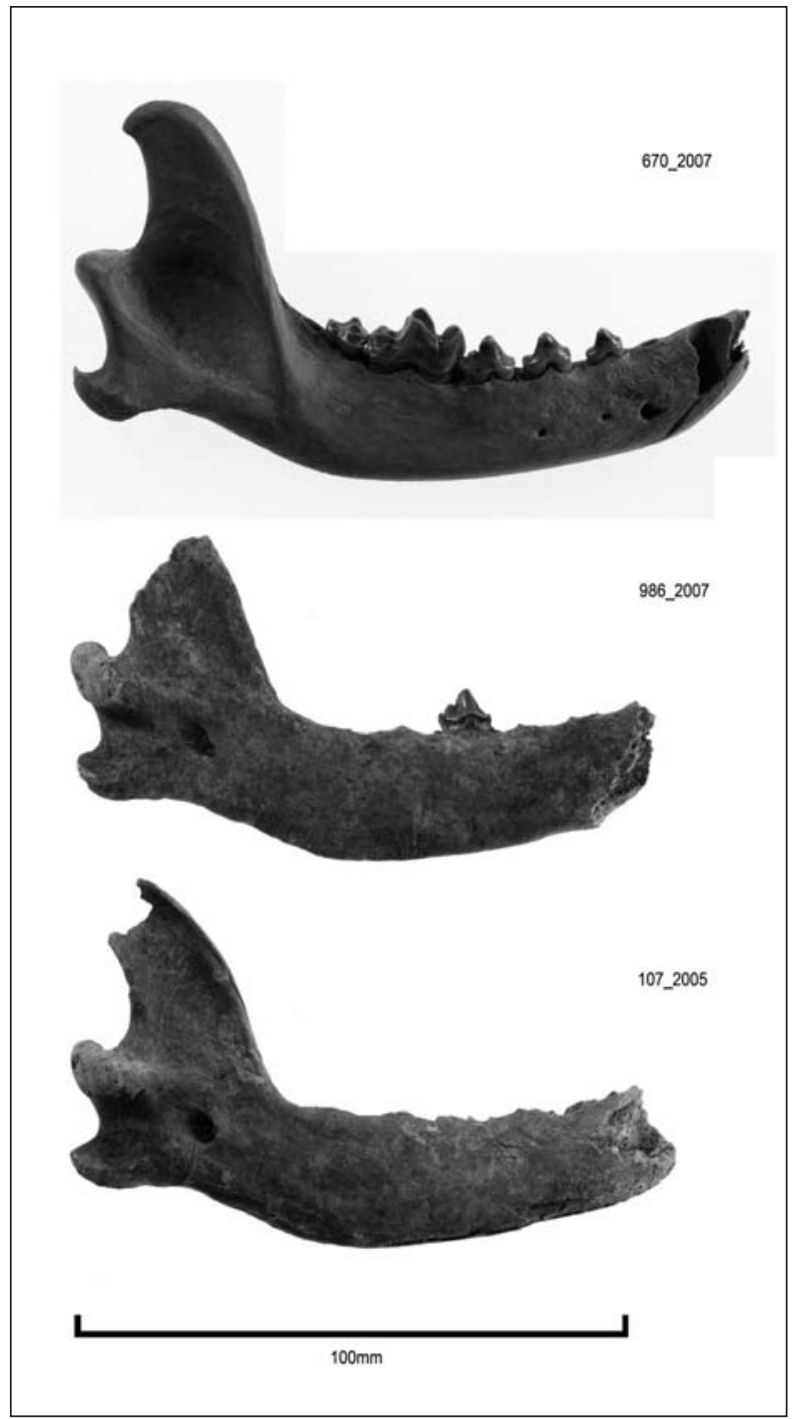

Figure 12. One right (top) and two left dog mandibles. The top mandible is from Area $D$ and shows a saw mark below the empty canine cavity, in keeping with purposeful removal of the canine. The bottom two, from Area $\mathrm{E}$, are broken through the canine cavity as a result of dog gnawing but are nonetheless relatively intact.

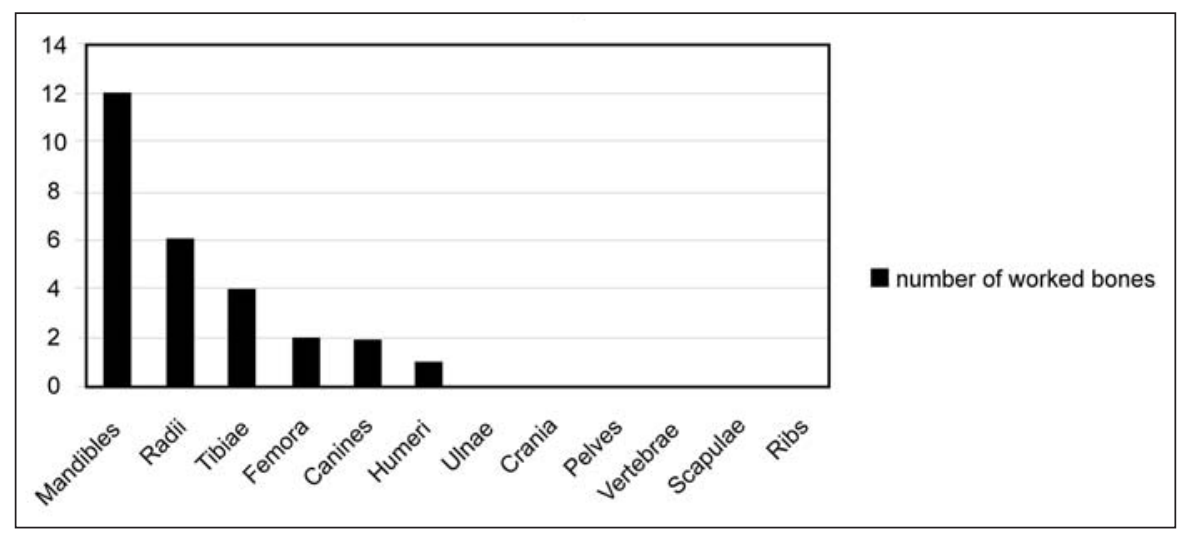

Figure 13. Total number of worked bones provided by each dog element. 


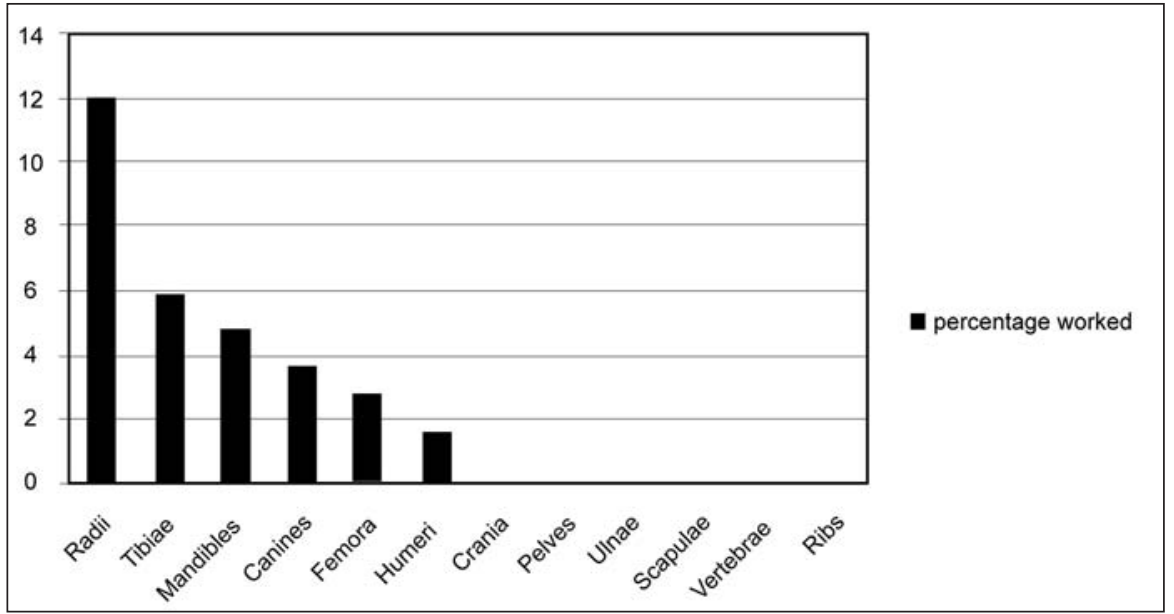

Figure 14. Percentage of each dog element that had been worked.

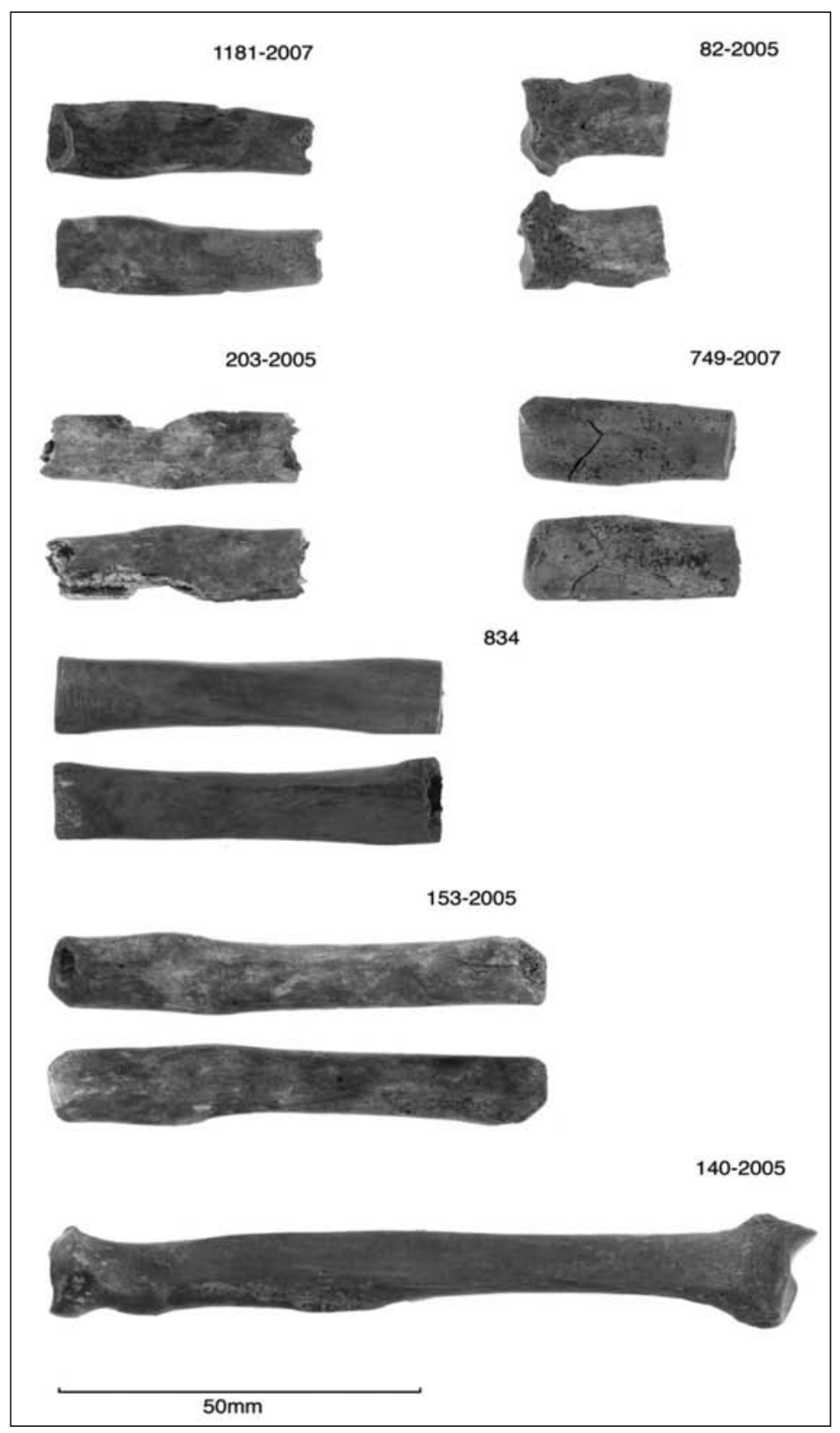

Figure 15. Dog radii. The bottom specimen (140-2005) is an intact radius for comparison. The six top specimens are all sawn and were found in Area E. 82-2005 in the top right corner is the sawn distal end of a radius, while the other five represent sawn lengths of radial shaft. 

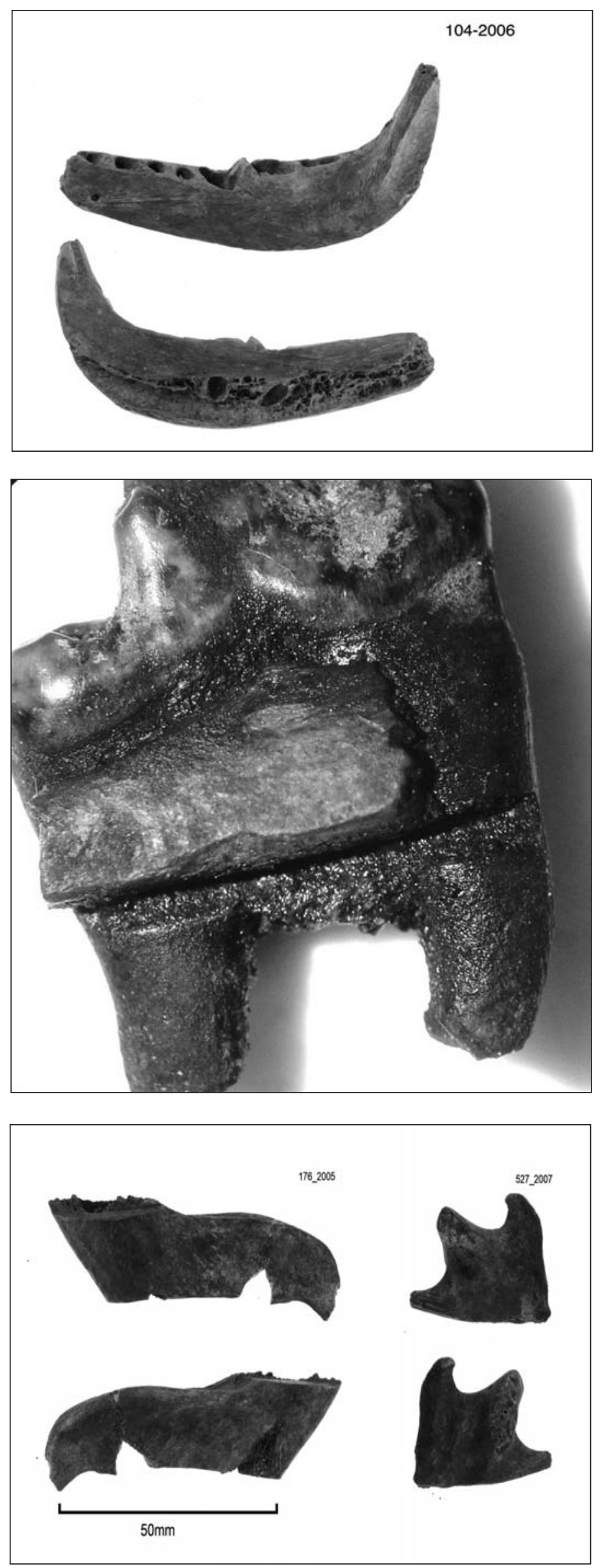

Figure 16. A'dog jaw point' found in Area D showing the dorsal (top) and ventral (bottom) aspects of the artefact. This is part of a twopiece fishhook made from a dog mandible by sawing off the ventral margin and the cranial end of the ascending ramus. The teeth have also been sawn out (see Figure 17) and the tooth sockets filed flat.

Figure 17. A sawn M1 dog molar (1178-2007) from Area E. The horizontal sawing groove is clearly identified just below the centre of the picture.

Figure 18. Two sawn fragments of dog mandible from Area E. The left specimen includes the coronoid process and is sawn at the rostral and cranial ends. The right specimen includes the articular and angular processes and is sawn only at the rostral end. 


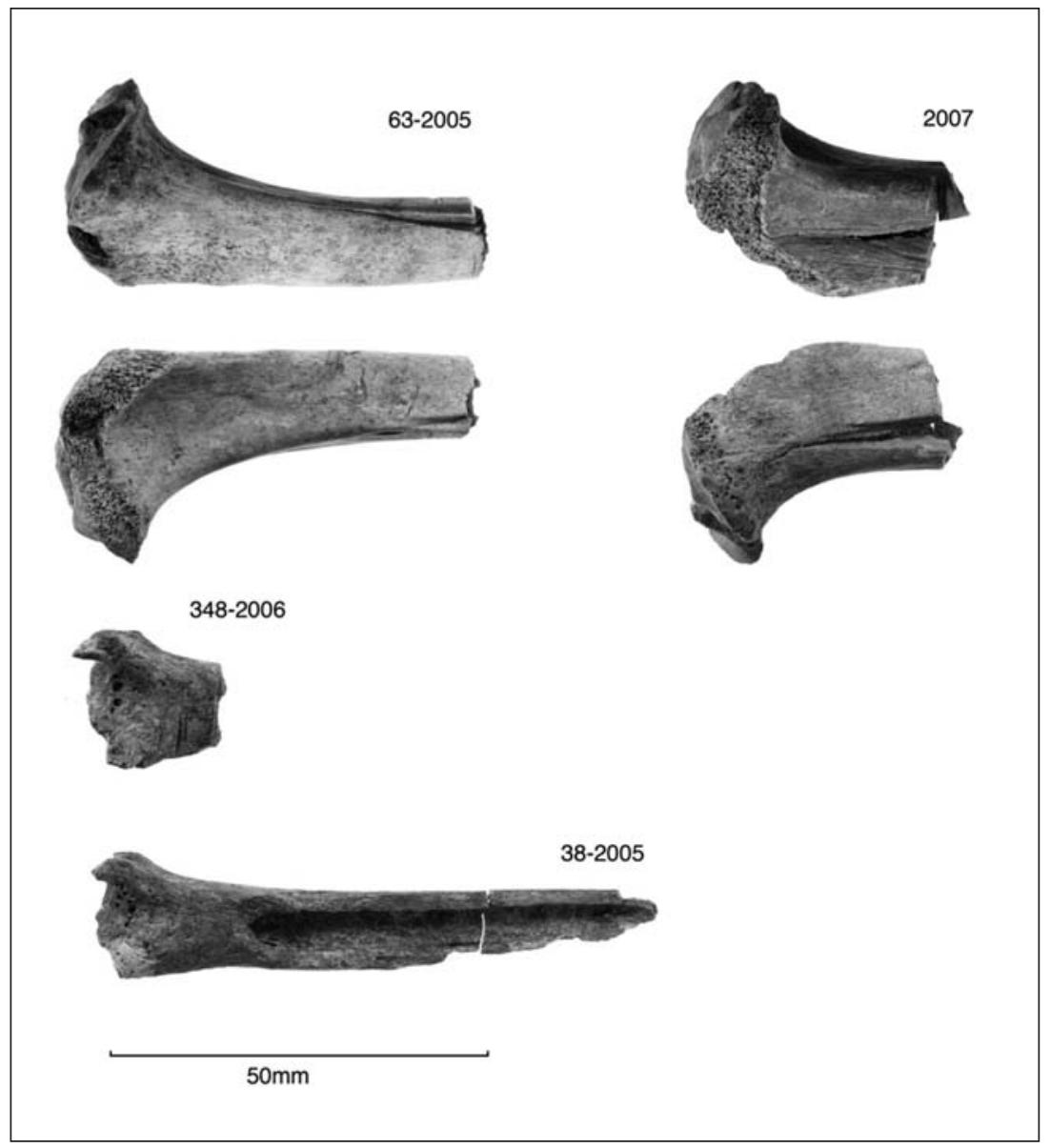

Figure 19. Sawn fragments of dog tibia from Area E. The top two specimens (63-2005 and 2007) are both proximal ends that have been sawn transversely and also have longitudinal grooves on the lateral and medial aspects, suggesting the manufacture of a consistent artefact, perhaps a chisel. 348-2006 (second from bottom) is the distal end of a tibia which has been sawn off. 38-2005 (at the bottom) is a rather poorly preserved chisel, also made from the distal end.

In general, the sawing at Kohika only proceeded to a certain depth and then the bone was snapped along the sawn groove. This sawing and snapping technique has been previously noted at other later-period Maori sites, such as Oruarangi (Furey 1996:162). Because it is most costefficient for prehistoric peoples with stone tools to cut through joints and around bones, rather than through bones, when butchering an animal, sawing is more likely be indicative of bonetool manufacture than butchery (Lyman 1987:263). Therefore, in combination with drilling and filing, the proportion of sawn bone is effectively a measure of the amount of worked bone at Kohika.

Table 6 records the number of dog bones with saw marks in Areas D and E and the proportion of each element which had been sawn. The proportion of each element which had been worked (either sawn, or in the case of one canine, drilled) is demonstrated graphically in Figure 13, while Figure 14 compares the actual number of worked items for each element.

Table 6 shows that virtually all sawn bone was found in Area E. The only two worked bones found in Area D were a mandible, which had had the canine purposely sawn out (Figure 12), and a 'dog jaw point' (Figure 16), which appeared incompletely finished and may have been accidentally lost in the lake. 
Figure 13 shows that in terms of the proportion worked compared with the number found, the element most commonly worked was the radius (Figure 15 shows examples of sawn radii). However, Figure 14 demonstrates that in terms of the actual numbers of worked items, there were more worked mandibles than any other element (Figures 16-18 show various examples of sawn mandibles and mandibular molars). Figures 13 and 14 both show other relatively soughtafter bones were the tibiae (Figure 19), femora and canines.

\section{Summary of results}

The NISP for all dog bone recovered from Kohika from 2005 to 2007 was 207; the MNE was 178; and the MNI was 20, based on left mandibles. Compared with the number of mandibles identified, there was a paucity of bones from other parts of the dog, and in particular, scapulae, ribs, vertebrae other than $\mathrm{C} 1$ and $\mathrm{C} 2$, and the small bones of the distal limbs were markedly under-represented.

There were also a number of differences in the dog bones retrieved from Area D, which was situated in Lake Kohika at the time of site occupation, and those recovered from Area E, which was on dry land during the same period. Greater proportions of all bones were found in Area D, with the exception of mandibles, radii and $\mathrm{C} 1$ and $\mathrm{C} 2$ vertebrae, and furthermore, all immature dog bones were found in Area D. Moreover, a far higher number of whole or near-whole bones were retrieved from Area D, whereas bones from Area E were more likely to be weathered and fragmented. Although an approximately equal number of dog-gnawed bones was found in both areas, bones had been reduced by dogs to a far greater extent in Area E, and furthermore, ratgnawed bones were only found in Area E.

In addition, sawn bone, which is the most effective archaeological measure of worked bone at Kohika, was almost exclusively found in Area E. The elements most frequently sawn were mandibles and radii, but tibiae and canines were also relatively sought after.

In summary, dog bones in Area $\mathrm{E}$ were more weathered, more worked and more gnawed than dog bones in Area D, which were more likely to be intact and more representative of a greater proportion of the dog skeleton.

\section{Comparison of the dog assemblage from 2005-2007 with the 1970s dog assemblage}

The bones recovered from Kohika during the 1970s have been reported by Irwin et al. (2004), and the principal analyst of the dog was M. Taylor. The MNI of 20 derived from the current assemblage is similar to the MNI of 16 calculated from the 1975-1977 excavations, although the latter was based on crania, rather than left mandibles (Irwin et al. 2004:200). When the two assemblages are combined, the MNI is 32 , based on left mandibles. Aside from the mandibles, crania are relatively frequent, with a combined MNI of 25 .

In addition to being dominated by mandibles and crania, the two assemblages have other similarities. In both, long bones are relatively under-represented, by a factor of two to three, while ribs, vertebrae, scapulae and small limb bones are under-represented by an even greater factor (Irwin et al. 2004:200). Furthermore, in both assemblages, the proportions of weathered and gnawed bones are similar (Irwin et al. 2004:201). Overall, 29 percent of dog bones from the 1975-1977 excavations were dog gnawed ( 55 bones in total), compared with 24 percent in the current assemblage ( 49 bones in total), and in both, dog-gnawed bones were distributed through all parts of the site. Rat-gnawed bones made up just over 6 percent of the 1970s collection (12 bones in total), versus 7 percent of the 2005-2007 collection (15 bones in total). In the 1970s 
assemblage, rat-gnawed bones were found in all parts of the site, including Area D, while they were restricted to Area E in the current assemblage. However, parts of Area D during the 1970 s were composed of artificially laid dry-sand floors, whereas all of Area D in the later excavations was situated in the lake (see Figure 1).

Weathering was identified on 11 percent of the dog bones found in the 1970s, although 22 percent of the bones from the Whakatane Historical Society site were weathered, whereas this was a feature of only 3 percent of Area D bones. The 2005-2007 assemblage had a similar overall proportion of weathered bones (15 percent) and once again, bones from Area D showed little evidence of weathering (less than 1 percent) compared with bones from Area E (38 percent).

The ages of the dogs in the two assemblages were also comparable. Based on 15 crania, Irwin et al. (2004:201) identified 12 adult dogs, two adolescent dogs and one juvenile dog within the 1970s assemblage, and the bones recovered since 2005 confirm most dogs at Kohika were killed after reaching maturity. On the basis of the mandibles and tooth-eruption patterns, there were a minimum of 18 dogs aged more than seven months, one dog aged about six months, and two dogs aged fewer than than four months in this latter assemblage.

These comparisons show the two Kohika assemblages, although taken from different parts of the village site, have many features in common. However one taphonomic variable which does differ between the two collections is the amount of sawn bone. Within Area E, 29 percent of dog bone recovered since 2005 had been sawn, which is a far greater proportion than the amount of sawn bone found in any area during the 1970s. In contrast, the amount of sawn bone in Area D is comparable (3.5 percent of bone from the 1970s assemblage and 1.6 percent of dog bone from the later collection).

\section{Discussion}

Why are there so many dog mandibles at Kohika and what has happened to the remainder of the dog skeletons?

One feature shared by both the Kohika dog-bone assemblages is a relatively high proportion of mandibles and, to a lesser extent, crania, while the remainder of the skeleton is under-represented. Of the dog bones recovered since 2005, this predominance of mandibles is especially noticeable in the drier parts of the site, as represented by Area E. In contrast, long bones are only half as frequent as they should be and there are even fewer bones from the majority of the axial skeleton. Based on the 1970s assemblage, Irwin and colleagues (2004:200) suggested three possible causes for this relative absence of trunk and limb bones, including dog gnawing with associated bone destruction, the loss of bones selected for industrial purposes, or 'the sharing of dog carcasses' through either trade or gift exchange. A fourth possibility, raised by Smith (1996:193) in relation to the dog remains from Shag River Mouth, is intra-site variability in the discard of certain parts of the butchered dog carcasses.

These alternatives are considered in turn.

Hypothesis 1: There has been a selective loss of the bones used for industrial purposes

Of the alternatives noted above, the loss of specific dog bones through their use in artefact manufacture is perhaps the least satisfactory explanation for the absence of parts of the dog skeleton. As the results show, mandibles were the most common element identified, but more mandibles than any other element had also been worked (Figure 6). Furthermore, in the less protected environment of Area E, two of the three elements found in greater proportions than Area D, namely mandibles and radii, were two of the elements which appeared to have been in the greatest demand for tool manufacture. In contrast, those bones mostly absent from Area E, 
such as pelves, scapulae, vertebrae, ribs and crania, seem never to have been worked. Therefore, rather than the industrial use of certain dog bones leading to the loss of particular skeletal remains, the Kohika results suggest the opposite might be true; the selection of certain bones for artefact manufacture may have actually assisted in their survival. The reasons bones selected for tool manufacture may have enjoyed preferential survival include the purposeful protection of these potentially useful elements from carnivore gnawing and weathering, and the intentional use of bones with the greatest density and therefore the greatest potential for survival for tool manufacture.

\section{Hypothesis 2: There was intra-site variability in the discard of different parts of the dog carcass}

At the 14th century Shag River Mouth site in East Otago, Smith (1996:193) has noted variation in the proportional representation of dog body parts in different parts of the site. Body parts with higher food value, including the forelimbs, predominated in the Swamp and upper layers of the Dune areas, whereas lower-value body parts, including the head, trunk and hind limbs, predominated in the lower Dune layers. Smith believed the lower Dune assemblages represented waste from initial carcass preparation, whereas the forelimb-dominated assemblages represented waste from human food consumption. He considered variation in bone discard was more likely to account for these assemblage differences than taphonomic processes.

The patterns identified by Smith at Shag River Mouth do not appear to account for the disparities between Areas D and $\mathrm{E}$ at Kohika. The lake was probably a dumping ground for food and bone waste from the adjacent household (see below). However, both forelimb and hindlimb bones remain half as frequent as expected, compared with mandibles, crania and pelves, and there is also a relative paucity of scapulae, vertebrae and ribs. This assemblage does not appear to represent a consistent assemblage of dog bones with low food value, as many of the bones from the trunk, limb extremities and hind limbs are missing. Since the bones in the lake are well preserved, some of these missing bones must have been discarded elsewhere. Similarly, it is not a forelimb-dominated assemblage, as might be anticipated in a midden predominately composed of human food waste.

In Area $\mathrm{E}$, there is also no clear pattern of high or low food-value bones. The Area $\mathrm{E}$ assemblage is dominated by mandibles, but $\mathrm{C} 1$ and $\mathrm{C} 2$ cervical vertebrae and radii are also more frequent than other bones. In contrast to the Shag River Mouth remains, these elements do not form a coherent collection of either butchery-waste or food-waste bones.

\section{Hypothesis 3: Parts of the dog carcasses have been removed from the site}

The possibility dog carcasses were sometimes moved off-site, perhaps through gifting or exchange, was raised by Smith (1981) as a possible explanation for the differential representation of body parts at the early-period Pig Bay site on Motutapu Island. Dog remains were prominent at Pig Bay, and as with Kohika, the MNI based on mandibles and crania was approximately twice that of all the long bones and about four times that derived from ribs and scapulae. Since there was no evidence that the limb bones, or any other dog bones, were being used to make tools, Smith believed the relative absence of long bones could indicate that the forelimbs and hind limbs were often detached from carcasses and shared or traded. He reported a historical account of dog carcasses being used as an exchange item, and the hypothesis receives possible support from some of the ethnohistorical accounts of Maori dogs collected by Allo (1970), which record how dog meat was considered a highly esteemed delicacy consumed on important occasions by priests and tattooists and prepared at feasts for distinguished visitors (Allo 1970:153-155). Certainly, it is conceivable that such a valued item was sometimes gifted, although the application of these ethnohistorical accounts for early-period sites such as Pig Bay may be questionable. 
Although dog carcasses could have been removed from Pig Bay and Kohika, there are some problems with the hypothesis. The importance of dog gnawing as a taphonomic variable was not fully realised by New Zealand archaeologists until M. Taylor's 1984 thesis on bone remains at Twilight Beach highlighted the effect dogs could have on faunal assemblages. A second problem arises from the similarity of the MNIs derived from each element at both Kohika and Pig Bay, where mandibles and crania dominated both assemblages, were twice as common as limb bones and were at least four times as common as scapulae and ribs. While this similarity may indicate the same body parts were being removed, it might also indicate similar taphonomic issues at the two sites. That this latter possibility is worth bearing in mind is underscored by a consideration of dog bones found in other New Zealand sites. Clark (1995:250-279) summarised dog-bone remains by skeletal element from 34 early and late-period sites from throughout the country and found mandibles were the most frequent element at 19 of these sites and crania the most frequent at another 10. Allo (1970:171-174) also identified crania and mandibles as the most common dog bones recovered from most New Zealand sites, especially from the Archaic period.

The Clark (1995) and Allo (1970) studies show Kohika and Pig Bay are not alone in being relatively rich in dog crania and mandibles compared with other dog bones. Are these similarities a reflection of analogous cultural practices or could they represent similar taphonomic processes? This latter possibility is now considered.

\section{Hypothesis 4: Selective bone loss is attributable to taphonomic processes}

Comparison of the dog bones from the protected anaerobic environment of Area D and the aerobic sandy environment of Area E shows weathering and animal gnawing were having a significant effect on the survival of dog bones at Kohika. But the comparison also shows these taphonomic variables did not affect all elements equally. For example, based on the remains from Area D, the MNI derived from crania, pelves and mandibles is quite similar (eight for crania, nine for pelves and 10 for mandibles), but the MNIs for these three elements in Area E are quite different (one for crania, one for pelves and 10 for mandibles). Figures 9 and 10 illustrate the marked effect of dog gnawing and weathering on crania and pelves in Area E compared with the preservation of these same elements in the lacustrine environment of Area D. In contrast, Figure 12 shows mandibles in Area E were relatively resistant to both weathering and dog gnawing. The same taphonomic processes affecting crania and pelves also acted on long bones and vertebrae, as shown in Figures 5, 8 and 11, and for the same reason, it is no surprise that relatively fragile bones such as scapulae, ribs and most vertebrae were completely absent from Area E.

The reason mandibles are more resistant to the taphonomic processes operating in Area $\mathrm{E}$ than most other dog bones is likely to be attributable to their greater density. Dog skeletons are adapted for mobility, and their bones, although strong, are relatively light and thin-walled (Taylor 1984:12-13). In fact, small elements can occasionally be difficult to distinguish from bird bones. As a result, dog bones are quite vulnerable to animal gnawing (Taylor 1984:172). Taylor $(1984: 23,91)$ has described how modern dogs can completely destroy certain elements such as vertebrae and even sheep and pig-sized long bones, and it is likely kuri would have had a similar potential to destroy dog bones. The one exception is the dog mandible, which is adapted to crushing and gnawing bone and is the strongest and most dense element in the skeleton (Taylor 1984:13, 171). As noted by Binford (1981:217) and Taylor (1984:24), bone survival is directly related to bone density, as it increases resistance to both weathering and animal gnawing, and it is probably this property which explains why mandibles are more likely to survive in archaeological sites. These same properties of bone density and strength also explain why Maori frequently selected the dog mandible for artefact manufacture. 
However, weathering, dog gnawing and bone density are not the only factors to consider at Kohika. Firstly, the amount of gnawing in any assemblage will be dictated by the size of the carnivore population. Given the number of dog bones and coprolites recovered from Kohika, the dog population in this village was possibly quite large and this also would have been an important variable. Secondly, the degree to which bones are reduced by animal gnawing is proportional to the time bones are exposed (Taylor 1984:24). Comparison of Areas D and E is again of interest in this regard, as it is clear the bones in Area D were exposed to dogs for a shorter period than the bones in Area E. As shown in Figures 6 and 7, dog-gnawed bones in Area D were still largely intact compared with gnawed bones in Area E (Figures 8-11). Furthermore, rat gnawing was only identified in Area E. Unlike dogs, which will only gnaw relatively fresh bones, it has been suggested rats will gnaw old bones, including sub-fossil bones (Taylor 1984:24, 26-27). Taken together, this suggests the bones in Area E were exposed to animal gnawing for prolonged periods, whereas the gnawed bones in Area D were transferred into the lake while still relatively fresh, having only been partly gnawed by dogs and not yet gnawed by rats. This dumping of relatively fresh, partly gnawed dog bones, especially larger bones such as crania, pelves and mandibles, into the lake was more likely to have been initiated by humans than dogs and suggests some form of tidying of the site by its occupants. This process may also account for the relative excess of crania, mandibles and pelves in Area $\mathrm{D}$, which is otherwise unexpected, given this area was protected from the taphonomic variables operating in Area E. Further proof the lake was used as a general rubbish dump is highlighted by the presence of numerous ungnawed whole dog elements in Area D, which must have been discarded while relatively fresh and perhaps still covered in soft tissues, and by the discovery of multiple bones from the same individual in one place, which was never identified in Area E. For example, the body of a virtually entire albatross, minus the wings, was found in the lake, as were eight long bones from a single immature dog.

A further factor which probably dictated both bone survival and the potential for recovery during archaeological excavations was bone size. Small bones generally survive destructive processes such as weathering and animal gnawing less well than large bones. Archaeological recovery techniques can compound this issue, and this could be relevant at Kohika where only selected parts of the deposit were sieved. Together, these two factors were probably at least partly responsible for the poor representation of smaller dog bones such as vertebrae, ribs and the small bones of the distal limbs.

In summary, there is no doubt taphonomic variables including animal gnawing, weathering, bone density, bone size and archaeological recovery techniques had a profound influence on the make up of the dog-bone remains in the drier parts of Kohika, as represented by Area E. Some of these factors are particularly well highlighted by comparing the dog assemblage in Area E with the wetland assemblage from Area D. Furthermore, it is likely these taphonomic processes are a significant part of the reason why dog mandibles were found so much more frequently than any other element in Area E. In contrast, the bones in Area D were in a protected environment, and weathering, animal gnawing, bone density and bone size were less relevant to the make up of this assemblage. Instead, it is likely that human bone dumping and tidying practices determined the survival of dog remains in this part of Kohika.

\section{Conclusion}

The large dog-bone assemblage from the late 17th century Maori lake village of Kohika provides a unique opportunity to compare the taphonomic processes affecting bones deposited in anaerobic wetland and aerobic dry-land environments. About half the dog bones recovered from 
Kohika between 2005 and 2007 came from an area that would have been located within the lake and outside the village palisade during occupation of the site. Most of these bones tended to be well preserved and were frequently completely intact, even if small and from immature dogs. Some elements, such as crania, pelves, scapulae, ribs and non-cervical vertebrae, were almost exclusively found in this part of the site. The remainder of the dog-bone assemblage came from inside the village palisade and was deposited in a dry and often sandy environment where the bones were exposed to weathering, human modification and prolonged dog and rat gnawing. Mandibles dominated this dry-land assemblage, which probably reflects the greater density of these elements compared with other dog bones and their relative resistance to weathering and dog gnawing. However, the preferential selection of certain bones, such as mandibles and radii, for tool manufacture may have also contributed to the greater frequency of these bones in the dry-land areas. Other bones, such as the remaining long bones, crania and most of the bones of the trunk, were infrequent in this part of the site, and this was most likely because they had been heavily reduced by gnawing and weathering, rather than because dog carcasses were being routinely moved from the village. Overall, the Kohika dog bones highlight the importance of considering taphonomy when assessing faunal remains, and moreover, the dry-land assemblage suggests taphonomic variables are likely to account for many of the discrepancies in dog bodypart representation in other dry-land New Zealand archaeological sites.

\section{Acknowledgements}

We are grateful for assistance from the landowners and farmers Dennis and Mary Sax and Cees Bruyn, and support from Ngati Awa, Te Whare Wanaga Awanuiarangi, the Whakatane and District Historical Society, and the Whakatane Museum and Gallery. Research funds were provided by the Marsden Fund.

\section{References}

Allen, M. and L. Nagaoka 2004. In the footsteps of Von Haast “... the discoveries something grand": the emergence of zooarchaeology in New Zealand. In L. Furey and S. Holdaway (eds), Change Through Time: 50 years of New Zealand Archaeology, pp. 193-214. Auckland: New Zealand Archaeological Association,.

Allo, J. 1970. The Maori dog: a study of the Polynesian dog of New Zealand. Unpublished MA, University of Auckland.

Anderson, A., T. Worthy and R. McGovern-Wilson 1996. Moa remains and taphonomy. In A. Anderson, B. Allingham and I. Smith (eds), Shag River mouth: the archaeology of an early Southern Maori village, pp. 200-213. Canberra: ANH publications, Australian National University.

Behrensmeyer, A. 1978. Taphonomic and ecologic information from bone weathering. Paleobiology 4:150-162.

Binford, L. 1981. Bones: ancient men and modern myths. New York: Academic Press.

Clark, G. 1995. The kuri in prehistory: a skeletal analysis of the extinct Maori dog. Unpublished MA, University of Otago.

Clark, G. 1997. Maori subsistence change: zooarchaeological evidence from the prehistoric dog of New Zealand. Asian Perspectives, 36:200-219. 
Furey, L. 1996 Oruarangi: the archaeology and material culture of a Hauraki pa. Auckland: Auckland Institute and Museum.

Irwin, G. 2004a. Kohika as a late northern Maori lake village. In G. Irwin (ed), Kohika: the archaeology of la late Maori lake village, pp. 239-248. Auckland: Auckland University Press.

Irwin, G. 2004b. Excavations and site history at Kohika. In G. Irwin (ed), Kohika: the archaeology of a late Maori lake village, pp. 45-75. Auckland: Auckland University Press.

Irwin, G., R. Nichol, M. Taylor, T. Worthy and I. Smith 2004. Faunal remains from Kohika. In G. Irwin (ed), Kohika: the archaeology of a late Maori lake village, pp. 198-216. Auckland: Auckland University Press.

Lyman, R. 1987. Archaeofaunas and butchery studies: a taphonomic perspective. Advances in Archaeological Method and Theory 10:249-337.

Smith, I. 1981. Mammalian fauna from an Archaic site on Motutapu Island, New Zealand. Records of the Auckland Institute and Museum, 18:95-105.

Smith, I. 1996. The mammal remains. In A. Anderson, B. Allingham and I. Smith (eds), Shag River mouth: the archaeology of an early Southern Maori village, pp. 185-199. Canberra: ANH publications, Australian National University.

Taylor, M. 1984. Bone refuse from Twilight Beach. Unpublished MA, University of Auckland. 